\title{
Fast-track surgery versus traditional perioperative care in laparoscopic colorectal cancer surgery: a meta-analysis
}

\author{
Jun-hua Zhao ${ }^{\dagger}$, Jing-xu Sun ${ }^{\dagger}$, Peng Gao, Xiao-wan Chen, Yong-xi Song, Xuan-zhang Huang, Hui-mian Xu \\ and Zhen-ning Wang*
}

\begin{abstract}
Background: Both laparoscopic and fast-track surgery (FTS) have shown some advantages in colorectal surgery. However, the effectiveness of using both methods together is unclear. We performed this meta-analysis to compare the effects of FTS with those of traditional perioperative care in laparoscopic colorectal cancer surgery.

Methods: We searched the PubMed, EMBASE, Cochrane Library, and Ovid databases for eligible studies until April 2014. The main end points were the duration of the postoperative hospital stay, time to first flatus after surgery, time of first bowel movement, total postoperative complication rate, readmission rate, and mortality.

Results: Five randomized controlled trials and 5 clinical controlled trials with 1,317 patients were eligible for analysis. The duration of the postoperative hospital stay (weighted mean difference [WMD], -1.64 days; $95 \%$ confidence interval $[\mathrm{Cl}],-2.25$ to $-1.03 ; \mathrm{p}<0.001)$, time to first flatus (WMD, -0.40 day; $95 \% \mathrm{Cl},-0.77$ to -0.04 ; $p=0.03$ ), time of first bowel movement (WMD, -0.98 day; $95 \% \mathrm{Cl},-1.45$ to $-0.52 ; p<0.001$ ), and total postoperative complication rate (risk ratio [RR], $0.67 ; 95 \% \mathrm{Cl}, 0.56-0.80 ; \mathrm{p}<0.001$ ) were significantly reduced in the FTS group. No significant differences were noted in the readmission rate ( $R R, 0.64 ; 95 \% \mathrm{Cl}, 0.41-1.01 ; \mathrm{p}=0.06)$ or mortality $(\mathrm{RR}, 1.55$; $95 \% \mathrm{Cl}, 0.42-5.71 ; p=0.51)$.

Conclusion: Among patients undergoing laparoscopic colorectal cancer surgery, FTS is associated with a significantly shorter postoperative hospital stay, more rapid postoperative recovery, and, notably, greater safety than is expected from traditional care.
\end{abstract}

Keywords: Fast track surgery, Laparoscopic surgery, Colorectal cancer

\section{Background}

Colorectal cancer is the third most commonly diagnosed cancer in men and the second most commonly diagnosed cancer in women [1]. Surgery, which is still the most common treatment for colorectal cancer, remains a high-risk procedure with clinically significant postoperative stress, complications, and a lengthy postoperative hospital stay. Standard elective colorectal resection is associated with a complication rate of $8 \%$ to $20 \%$ and a postoperative stay of 8 to 12 days [2]. The high complication

\footnotetext{
* Correspondence: josieon826@sina.cn

${ }^{\dagger}$ Equal contributors

Department of Surgical Oncology and General Surgery, the First Hospital of China Medical University, Shenyang 110001, People's Republic of China
}

rate and long hospital stay necessitate changes to the management of colorectal cancer.

Laparoscopy for colorectal surgery was first reported in 1991 by Fowler [3]. Many studies have shown that this technique can result in a shorter postoperative hospital stay, a lower requirement for postoperative pain control, and more rapid gastrointestinal recovery than can open surgery, without comprising safety $[4,5]$. Fasttrack surgery (FTS), also termed an enhanced recovery program, was initiated by the Kehlet group in $2001[6,7]$. This program combines several methods, such as patient education, epidural or regional anesthesia, minimally invasive techniques, no routine use of drains or nasogastric tubes, optimal pain control, and early enteral nutrition and ambulation [6]. Its purpose is to reduce 
the stress response, shorten the hospital stay, improve recovery, and reduce the complication rate [2]. Many randomized controlled trials (RCTs) and meta-analyses have demonstrated that FTS is applicable and effective in colorectal surgery [8-11].

Indeed, both the laparoscopic technique and FTS are able to enhance recovery and shorten the postoperative hospital stay. Hypothetically, we can assume that incorporation of FTS into laparoscopic surgery can result in the most rapid postoperative recovery. However, this theory is not evidenced-based because very few published comprehensive systematic reviews or meta-analyses on the enhanced recovery effects of FTS in patients undergoing laparoscopic colorectal surgery have been retrieved from the databases. At the same time, well-designed comprehensive studies to provide solid evidence for further studies are needed [12,13]. Moreover, the individual studies that have investigated this issue have yielded conflicting results. Thus, we conducted the present meta-analysis of published studies to evaluate the effects of FTS in patients undergoing laparoscopic colorectal cancer surgery.

\section{Methods}

\section{Search strategy}

Publications were identified by searching major medical databases, including PubMed, EMBASE, the Cochrane Library, and Ovid, for all articles published until 1 April 2014. We used the following key words: "fast track", "multimodal rehabilitation", "enhanced recovery", "colorectal surgery", "colorectal resection", "large intestine", "colon", "rectum", "sigmoid", "minimally invasive surgery", and "laparoscopic". We then broadened the search range by browsing the related summary, methods, and reference sections of retrieved articles. The language used in publications was restricted to English.

\section{Inclusion and exclusion criteria}

Studies that met the following criteria were included: (1) publications in English comparing FTS with conventional perioperative care in patients undergoing laparoscopic colorectal cancer surgery, (2) full text of the article available with a clear description of the FTS protocol used in the study, and (3) reporting of at least one of the outcome measures mentioned below. If overlap between authors or centers was present, the higher-quality or more recent study was selected. Studies were excluded for the following reasons: FTS and traditional perioperative care were not compared or patients with benign colorectal disease were included, or the study did not provide an FTS protocol or the protocol applied fewer than six fast-track elements.

\section{Outcome measures, data extraction, and assessment of risk of bias}

The primary outcomes included the duration of the postoperative hospital stay, time to first flatus, and time of first bowel movement, each measured in days. We also included the total postoperative complication rate (complications defined based on the Memorial SloanKettering Cancer Center complication reporting system [14]), readmission rate, and 30-day postoperative mortality rate. Two authors independently extracted the data from the full text articles using a unified data sheet. The RCTs were evaluated using the Jadad composite scale. High-quality trials were those that scored $\geq 3$ of a maximum possible score of 5 . The controlled clinical trials were evaluated using the Newcastle-Ottawa Scale. Highquality trials were those that scored $\geq 7$ of a maximum possible score of 9 . Moderate-quality trials scored $\geq 5$. Any disagreement was presented to a third author and resolved by discussion among the investigators.

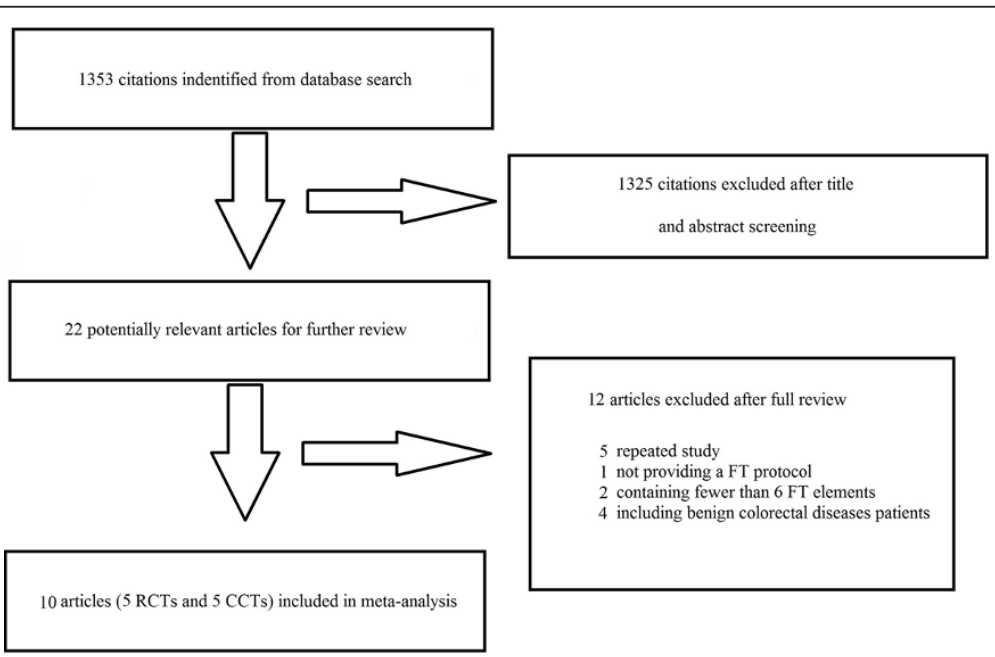

Figure 1 Flow chart of articles selection. 
Table 1 Main characteristics of including studies

\begin{tabular}{|c|c|c|c|c|c|c|c|c|c|c|c|c|c|c|c|c|c|c|}
\hline \multirow[t]{3}{*}{ Reference } & \multirow[t]{3}{*}{ Year } & \multirow[t]{3}{*}{ Place } & \multirow[t]{3}{*}{ Type } & \multirow{2}{*}{\multicolumn{2}{|c|}{$\begin{array}{l}\text { Number of } \\
\text { patients }\end{array}$}} & \multirow[t]{3}{*}{ Follow-up } & \multirow{2}{*}{\multicolumn{2}{|c|}{$\begin{array}{l}\text { Age Mean } \pm \text { SD/ } \\
\text { median (range) }\end{array}$}} & \multirow{2}{*}{\multicolumn{2}{|c|}{$\begin{array}{c}\text { Sex } \\
\text { (male/female) }\end{array}$}} & \multicolumn{4}{|c|}{ ASA } & \multicolumn{4}{|c|}{ TNM stage* } \\
\hline & & & & & & & & & & & \multicolumn{2}{|c|}{ FT } & \multicolumn{2}{|c|}{ TC } & \multicolumn{2}{|c|}{ FT } & \multicolumn{2}{|c|}{ TC } \\
\hline & & & & FT & $\mathrm{TC}$ & & FT & $\mathrm{TC}$ & FT & TC & $\mathrm{I} / \mathrm{II}$ & $\mathrm{III} / \mathrm{IV}$ & $\mathrm{I} / \mathrm{II}$ & III/IV & sstage II & >stage II & sstage II & >stage II \\
\hline Lee [19] & 2011 & Korea & $\mathrm{RCT}$ & 46 & 54 & 1 month & $61.9 \pm 11.2$ & $60.6 \pm 10.0$ & $26 / 20$ & $30 / 24$ & 43 & 2 & 51 & 3 & 23 & 21 & 31 & 21 \\
\hline Vlug [18] & 2011 & Netherlands & RCT & 100 & 109 & 30 days & $66 \pm 8.6$ & $68 \pm 8.8$ & $53 / 47$ & $68 / 41$ & 82 & 21 & 87 & 22 & NA & NA & NA & NA \\
\hline Q.Wang [16] & 2012 & China & RCT & 40 & 38 & More than one month & $71(65-81)$ & $72(65-82)$ & $22 / 18$ & $20 / 18$ & NA & NA & NA & NA & 18 & 22 & 18 & 20 \\
\hline G.Wang [17] & 2012 & China & $\mathrm{RCT}$ & 40 & 40 & 30 days & $55.7 \pm 17.3$ & $56.1 \pm 14.6$ & $27 / 13$ & $26 / 14$ & 33 & 7 & 36 & 4 & 24 & 16 & 27 & 13 \\
\hline Feng [20] & 2014 & China & $\mathrm{RCT}$ & 57 & 59 & 4 weeks & $54.0 \pm 12.0$ & $56.3 \pm 11.5$ & $36 / 21$ & $40 / 19$ & 57 & 0 & 59 & 0 & 35 & 22 & 30 & 29 \\
\hline Esteban [23] & 2014 & Spain & CCT & 150 & 56 & 30 days & $68.04 \pm 9.9$ & $64.8 \pm 14$ & $70 / 80$ & $28 / 28$ & 99 & 49 & 44 & 11 & NA & NA & NA & NA \\
\hline Gouvas [21] & 2012 & Greece & ССТ & 42 & 33 & 1 month & 64(31-83) & $68(34-85)$ & $22 / 20$ & $11 / 22$ & 37 & 5 & 29 & 4 & 35 & 7 & 28 & 5 \\
\hline Poon [22] & 2010 & Chinese HongKong & ССТ & 96 & 84 & Till discharge & $72(31-94)$ & $72(46-92)$ & $51 / 45$ & $50 / 34$ & 83 & 13 & 68 & 16 & 54 & 42 & 43 & 41 \\
\hline Vassiliki [24] & 2009 & USA & ССТ & 82 & 115 & Till discharge & $68.2 \pm 13.4$ & $69.3 \pm 11.9$ & $36 / 46$ & $60 / 55$ & 56 & 26 & 76 & 39 & NA & NA & NA & NA \\
\hline Huibers [25] & 2012 & Netherlands & $\mathrm{CCT}$ & 43 & 33 & Till discharge & $66(36-79)$ & $64(27-88)$ & $27 / 16$ & $22 / 11$ & 33 & 10 & 26 & 7 & 23 & 20 & 26 & 7 \\
\hline
\end{tabular}

FT: fast track; TC: traditional care; RCT: randomized controlled trails; CCT: clinical controlled trails.

*: the study by Lee included a few submucosal lipoma and lymphoma patients that cannot be staged by TNM. 


\section{Statistical analysis}

This meta-analysis was conducted with Review Manager software (RevMan version 5.2; Cochrane Collaboration). The risk ratio (RR) was used for statistical analysis of dichotomous variables, and the weighted mean difference (WMD) was used to analyze continuous variables. Both were reported with 95\% confidence intervals (CIs). For continuous variables, if the study provided medians and ranges instead of means and standard deviations, we calculated the means and standard deviations according to the methods provided by Hozo et al. [15]. If the median and interquartile range were provided, the median was used as the mean and the interquartile range divided by 1.35 was used as the standard deviation as described in the Cochrane handbook. And subgroup analysis was performed based on study design and each FT element. Heterogeneity was determined using the $x^{2}$ test or Cochran $Q$ statistic, and $\mathrm{I}^{2}$ was used to quantify heterogeneity. A p value of $<0.10$ with an $\mathrm{I}^{2}$ value of $>50 \%$ was indicative of substantial heterogeneity. The inverse variance method with a fixed-effects model was applied if no heterogeneity was considered, whereas a randomeffects model was used in opposite cases. Publication bias was tested using a funnel plot. The $\mathrm{p}$ value threshold for statistical significance was set at 0.05 .

\section{Results}

\section{Eligible studies}

By searching the above-mentioned key words, 1,353 citations were identified. Five RCTs [16-20] and five CCTs [21-25] were considered eligible for the meta-analysis (Figure 1). Analysis was performed on 1,317 patients in the FTS group $(n=696)$ or traditional care group $(n=$ 621). Detailed patient characteristics are listed in Table 1. The included studies had a clearly defined FTS protocol, which included at least six fast-track elements. The detailed information on the fast-track elements included in each study is listed in Table 2. All five RCTs had Jadad scores of $\geq 3$ and were thus considered to be high-quality studies (Table 3). All of the CCTs scored 6 on the Newcastle-Ottawa Scale and were thus considered to be moderate-quality studies (Table 4).

\section{Duration of postoperative hospital stay}

All of the studies [16-25] reported the duration of the postoperative hospital stay. Notably, the outcome of the study by Huibers et al. [25] deviated significantly from the normal distribution. Thus, the outcome was not included in the meta-analysis. After pooling the data, there was a significantly shorter postoperative hospital stay favoring FTS (WMD, -1.64 days; $95 \% \mathrm{CI},-2.25$ to -1.03 ; $\mathrm{p}<0.001)$. The difference remained significant based on subgroup analysis of RCTs and CCTs. A random-effects model was used for significant heterogeneity between the studies $\left(\mathrm{p}<0.001, \mathrm{I}^{2}=81 \%\right)$ (Figure 2).

\section{Time to first flatus}

Five studies [16,18-20,22] reported the time to first flatus, which was significantly shorter in the FTS group than in the traditional care group (WMD, -0.40 day; $95 \% \mathrm{CI},-0.77$ to $-0.04 ; \mathrm{p}=0.03$ ). A random-effects model was used for significant heterogeneity between studies $\left(\mathrm{p}<0.001, \mathrm{I}^{2}=88 \%\right)$ (Figure 3$)$.

\section{Time of first bowel movement}

Seven studies [16,18-21,24,25] reported the time that elapsed until the first postoperative bowel movement. Notably, the outcome of the study by Huibers et al. [25] departed significantly from the normal distribution. Thus, the outcome was not included in the meta-analysis. After

Table 2 Details about fast track elements of including studies

\begin{tabular}{|c|c|c|c|c|c|c|c|c|c|c|c|c|c|c|c|c|c|c|c|}
\hline \multirow[t]{2}{*}{ Reference } & \multirow[t]{2}{*}{ Type } & \multicolumn{5}{|c|}{ Preoperative } & \multicolumn{5}{|c|}{ Perioperative } & \multicolumn{7}{|c|}{ Postoperative } & \multirow[t]{2}{*}{ Total } \\
\hline & & A & B & $\mathrm{C}$ & D & $\mathrm{E}$ & $F$ & G & $\mathrm{H}$ & 1 & J & K & $\mathbf{L}$ & $M$ & $\mathbf{N}$ & 0 & $P$ & $\mathbf{Q}$ & \\
\hline Lee [19] & $\mathrm{RCT}$ & $\sqrt{ }$ & & & & $\sqrt{ }$ & & & & & & $\sqrt{ }$ & & $\sqrt{ }$ & $\sqrt{ }$ & & $\sqrt{ }$ & $\sqrt{ }$ & 7 \\
\hline Vlug [18] & RCT & $\sqrt{ }$ & $\sqrt{ }$ & $\sqrt{ }$ & $\sqrt{ }$ & $\sqrt{ }$ & & $\sqrt{ }$ & $\sqrt{ }$ & $\sqrt{ }$ & $\sqrt{ }$ & $\sqrt{ }$ & $\sqrt{ }$ & $\sqrt{ }$ & $\sqrt{ }$ & $\sqrt{ }$ & $\sqrt{ }$ & $\sqrt{ }$ & 16 \\
\hline Q.Wang [16] & RCT & $\sqrt{ }$ & $\sqrt{ }$ & $\sqrt{ }$ & $\sqrt{ }$ & $\sqrt{ }$ & & & $\sqrt{ }$ & & & & & $\sqrt{ }$ & $\sqrt{ }$ & & $\sqrt{ }$ & $\sqrt{ }$ & 10 \\
\hline G.Wang [17] & $\mathrm{RCT}$ & $\sqrt{ }$ & $\sqrt{ }$ & $\sqrt{ }$ & & $\sqrt{ }$ & & & $\sqrt{ }$ & & & $\sqrt{ }$ & $\sqrt{ }$ & $\sqrt{ }$ & $\sqrt{ }$ & & & $\sqrt{ }$ & 10 \\
\hline Feng [20] & $\mathrm{RCT}$ & & $\sqrt{ }$ & $\sqrt{ }$ & & & & $\sqrt{ }$ & & $\sqrt{ }$ & & & $\sqrt{ }$ & $\sqrt{ }$ & $\sqrt{ }$ & $\sqrt{ }$ & & $\sqrt{ }$ & 9 \\
\hline Esteban [23] & $\mathrm{CCT}$ & $\sqrt{ }$ & $\sqrt{ }$ & $\sqrt{ }$ & & $\sqrt{ }$ & $\sqrt{ }$ & $\sqrt{ }$ & $\sqrt{ }$ & & & $\sqrt{ }$ & $\sqrt{ }$ & $\sqrt{ }$ & $\sqrt{ }$ & & $\sqrt{ }$ & $\sqrt{ }$ & 13 \\
\hline Gouvas [21] & $\mathrm{CCT}$ & $\sqrt{ }$ & $\sqrt{ }$ & & & $\sqrt{ }$ & $\sqrt{ }$ & $\sqrt{ }$ & $\sqrt{ }$ & & & $\sqrt{ }$ & & $\sqrt{ }$ & $\sqrt{ }$ & & & & 9 \\
\hline Poon [22] & $\mathrm{CCT}$ & $\sqrt{ }$ & & & & $\sqrt{ }$ & & & & $\sqrt{ }$ & & $\sqrt{ }$ & $\sqrt{ }$ & $\sqrt{ }$ & $\sqrt{ }$ & & & $\sqrt{ }$ & 8 \\
\hline Vassiliki [24] & $\mathrm{CCT}$ & $\sqrt{ }$ & & $\sqrt{ }$ & & & & & & & & & & $\sqrt{ }$ & $\sqrt{ }$ & $\sqrt{ }$ & & $\sqrt{ }$ & 6 \\
\hline Huibers [25] & $\mathrm{CCT}$ & $\sqrt{ }$ & $\sqrt{ }$ & $\sqrt{ }$ & $\sqrt{ }$ & $\sqrt{ }$ & $\sqrt{ }$ & $\sqrt{ }$ & $\sqrt{ }$ & & & $\sqrt{ }$ & & $\sqrt{ }$ & $\sqrt{ }$ & $\sqrt{ }$ & $\sqrt{ }$ & $\sqrt{ }$ & 14 \\
\hline
\end{tabular}

$\mathrm{RCT}$ : randomized controlled trails; CCT: clinical controlled trails.

A: patients education B: preoperative feeding C: No bowel preparation D: No premedication E: fluid restriction F: high O2 concentration during operation G: prevention of hypothermia during surgery $\mathrm{H}$ : epidural analgesia I: wound infiltration with local analgesia J: minimally invasive incisions K: No routine use of NG tube L: No routine use of drains M: early mobilization N: enforced early postoperative oral feeding O: No morphine use P: standard laxatives Q: early remove bladder catheter. 
Table 3 The risk of bias of RCTS (Jadad scale)

\begin{tabular}{cccccc}
\hline Reference & Randomization Blinding & $\begin{array}{c}\text { Withdraw } \\
\text { and } \\
\text { dropout }\end{array}$ & $\begin{array}{c}\text { Jadad's Quality } \\
\text { score }\end{array}$ & \\
\hline Lee [19] & 2 & 0 & 1 & 3 & High \\
Vlug [18] & 2 & 1 & 1 & 4 & High \\
Q.Wang [16] & 2 & 0 & 1 & 3 & High \\
G.Wang [17] & 2 & 0 & 1 & 3 & High \\
Feng [20] & 2 & 1 & 1 & 4 & High \\
\hline
\end{tabular}

Randomization: randomization was described with appropriate method: 2 score, randomization was described without appropriate method: 1 score, no randomization: 0 score.

Blinding: blinding was performed on all doctors and patients: 2 score, blinding was partially performed on doctors and patients: 1 score, no blinding: 0 score; Withdraw and dropout: the reason of withdraw and dropout was described: 1 score, the reason of withdraw and dropout was not described: 0 score. Quality: High-quality trials should score $\geq 3$.

pooling the data, the time of the first bowel movement was significantly shorter in the FTS group than in the traditional care group (WMD, -0.98 day; $95 \% \mathrm{CI},-1.45$ to -0.52 ; $\mathrm{p}<0.001)$; however, the difference was not statistically significant based on the subgroup analysis of CCTs. A random-effects model was used for significant heterogeneity between studies ( $\mathrm{p}<0.001, \mathrm{I}^{2}=86 \%$ ) (Figure 4 ).

\section{Total postoperative complication rate}

All of the studies [16-25] reported the complication rate. A total of 149 patients in the FTS group developed complications, while 203 patients in the traditional care group developed complications. The results of the metaanalysis showed that FTS is associated with a significantly lower complication rate (RR, 0.67; 95\% CI, 0.56$0.80 ; \mathrm{p}<0.001)$. Subgroup analysis of the RCTs and CCTs also showed a significant difference favoring FTS. There was no significant heterogeneity between studies $\left(\mathrm{p}=0.05, \mathrm{I}^{2}=47 \%\right)$ (Figure 5).

\section{Rate of readmission}

Nine [17-25] of the 10 studies reported the rate of readmission. Thirty patients in the FTS group and 37 patients in the traditional care group required readmission. Based on the meta-analysis, patients in the FTS group had a lower readmission rate; however, the difference was not significant (RR, 0.64; 95\% CI, 0.41-1.01; $\mathrm{p}=$ 0.06). Additionally, subgroup analysis of RCTs and CCTs did not show a significant difference between the two groups. There was no significant heterogeneity between the studies $\left(\mathrm{p}=0.97, \mathrm{I}^{2}=0 \%\right)$ (Figure 6).

\section{Thirty-day postoperative mortality}

Eight [17-21,23-25] of the 10 studies reported mortality rates. Five patients in the FTS group and two in the traditional group died 30 days after surgery. Based on the meta-analysis, no difference was present between the two groups (RR, 1.55; 95\% CI, 0.42-5.71; $\mathrm{p}=0.51$ ). The subgroup analysis of RCTs and CCTs showed the same results as did the overall meta-analysis. There was no significant heterogeneity between the studies $(\mathrm{p}=0.94$, $\mathrm{I}^{2}=0 \%$ ) (Figure 7).

\section{Subgroup analysis based on fast-track elements}

Subgroup analysis was performed based on each fasttrack element for the duration of the postoperative hospital stay and total postoperative complication rate. For the duration of the postoperative hospital stay, the difference between the FTS group and traditional care group was not significant in the studies without the element "no bowel preparation". For the total postoperative complication rate, the differences between the FTS group and traditional care group were not significant in the studies with the elements "no premedication", "prevention of hypothermia", "wound infiltration with local analgesia", "minimally invasive incisions", "no routine use of drains", and "no morphine use", separately. All other subgroup analysis results showed significant differences favoring FTS. The results are summarized in Table 5.

\section{Other outcomes}

Data on some other outcomes were impossible to subject to meta-analysis because of incompatibility or the limited study quantity. Thus, we performed a systemic review. Pain control or pain intensity after surgery was reported in four studies [18-21], three of which [19-21]

Table 4 The risk of bias of RCTS (NOS)

\begin{tabular}{|c|c|c|c|c|c|c|c|c|c|c|c|}
\hline \multirow[t]{2}{*}{ Reference } & \multicolumn{4}{|c|}{ Selection } & \multicolumn{2}{|c|}{ Comparability } & \multicolumn{3}{|c|}{ Outcome } & \multirow[t]{2}{*}{ TOTAL } & \multirow[t]{2}{*}{ Quality } \\
\hline & REC & SNEC & $\mathrm{AE}$ & DO & SC & AF & AO & FU & FUO & & \\
\hline Esteban [23] & 1 & 0 & 1 & 1 & 0 & 0 & 1 & 1 & 1 & 6 & Moderate \\
\hline Gouvas [21] & 1 & 0 & 1 & 1 & 0 & 0 & 1 & 1 & 1 & 6 & Moderate \\
\hline Poon [22] & 1 & 1 & 1 & 1 & 0 & 0 & 1 & 0 & 1 & 6 & Moderate \\
\hline Vassiliki [24] & 1 & 1 & 1 & 1 & 0 & 0 & 1 & 0 & 1 & 6 & Moderate \\
\hline Huibers [25] & 1 & 1 & 1 & 1 & 0 & 0 & 1 & 0 & 1 & 6 & Moderate \\
\hline
\end{tabular}

REC: representativeness of the exposed cohort; SNEC: selection of the non-exposed cohort; AE: ascertainment of exposure; DO: demonstration that outcome of interest was not present at start of study; SC: study controls for age, sex; AF: study controls for any additional factors; AO: assessment of outcome; FU: follow-up long enough for outcomes to occur; FUO: adequacy of follow-up of cohorts. 


\begin{tabular}{|c|c|c|c|c|c|c|c|c|c|c|}
\hline \multirow[b]{2}{*}{ Study or Subqroup } & \multicolumn{3}{|c|}{ Fast track surgery } & \multicolumn{3}{|c|}{ Traditional care } & \multirow{2}{*}{\multicolumn{2}{|c|}{$\begin{array}{c}\text { Mean Difference } \\
\text { Weight } I V \text {, Random, } 95 \% \mathrm{Cl} \\
\end{array}$}} & \multirow{2}{*}{\multicolumn{2}{|c|}{$\begin{array}{l}\text { Mean Difference } \\
\text { IV, Random, } 95 \% \mathrm{Cl}\end{array}$}} \\
\hline & Mean & SD & Total & Mean & SD & Total & & & & \\
\hline \multicolumn{11}{|c|}{ (2) } \\
\hline Feng 2014 & 5.05 & 1.38 & 57 & 6.98 & 2.26 & 59 & $13.0 \%$ & $-1.93[-2.61,-1.25]$ & $\rightarrow$ & \\
\hline G.Wang 2012 & 5.2 & 3.9 & 40 & 6.3 & 4.7 & 40 & $6.2 \%$ & $-1.10[-2.99,0.79]$ & & \\
\hline Lee 2011 & 7 & 1.48 & 46 & 8 & 1.48 & 54 & $13.5 \%$ & $-1.00[-1.58,-0.42]$ & - & \\
\hline Q.Wang 2012 & 5.5 & 0.74 & 40 & 7 & 1.48 & 38 & $13.9 \%$ & $-1.50[-2.02,-0.98]$ & $=$ & \\
\hline Vlug 2011 & 5 & 2.22 & 100 & 6 & 3.33 & 109 & $12.4 \%$ & $-1.00[-1.76,-0.24]$ & 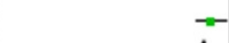 & \\
\hline Subtotal $(95 \% \mathrm{Cl})$ & & & 283 & & & 300 & $59.0 \%$ & $-1.35[-1.72,-0.99]$ & $\diamond$ & \\
\hline \multicolumn{11}{|c|}{$\begin{array}{l}\text { Heterogeneity: } \text { Tau }^{2}=0.04 ; \mathrm{Chi}^{2}=5.38, \mathrm{df}=4(P=0.25) ; I^{2}=26 \% \\
\text { Test for overall effect: } Z=7.21(P<0.00001)\end{array}$} \\
\hline \multicolumn{11}{|l|}{$2.1 .2 \mathrm{CCT}$} \\
\hline Esteban 2014 & 5 & 2.22 & 150 & 9 & 4.44 & 56 & $9.6 \%$ & $-4.00[-5.22,-2.78]$ & $\rightarrow$ & \\
\hline Gouvas 2012 & 4 & 2.25 & 42 & 8 & 3.75 & 33 & $8.2 \%$ & $-4.00[-5.45,-2.55]$ & & \\
\hline Poon 2010 & 4 & 3.5 & 96 & 4 & 5.3 & 84 & $8.9 \%$ & $0.00[-1.33,1.33]$ & - & \\
\hline Vassiliki 2009 & 3 & 0.74 & 82 & 4 & 2.22 & 115 & $14.3 \%$ & $-1.00[-1.44,-0.56]$ & - & \\
\hline Subtotal $(95 \% \mathrm{Cl})$ & & & 370 & & & 288 & $41.0 \%$ & $-2.21[-4.04,-0.38]$ & & \\
\hline \multicolumn{11}{|c|}{$\begin{array}{l}\text { Heterogeneity: } \mathrm{Tau}^{2}=3.12 ; \mathrm{Chi}^{2}=37.40, \mathrm{df}=3(\mathrm{P}<0.00001) ; \mathrm{I}^{2}=92 \% \\
\text { Test for overall effect: } Z=2.37(P=0.02)\end{array}$} \\
\hline Total $(95 \% \mathrm{Cl})$ & & & 653 & & & 588 & $100.0 \%$ & $-1.64[-2.25,-1.03]$ & $\boldsymbol{\gamma}$ & \\
\hline \multicolumn{9}{|c|}{$\begin{array}{l}\text { Heterogeneity: } \text { Tau }^{2}=0.63 ; \mathrm{Chi}^{2}=42.83, \mathrm{df}=8(P<0.00001) ; \mathrm{I}^{2}=81 \% \\
\text { Test for overall effect: } Z=5.28(P<0.00001) \\
\text { Test for subgroup differences: } \mathrm{Chi}^{2}=0.81 . \mathrm{df}=1(\mathrm{P}=0.37) . \mathrm{I}^{2}=0 \%\end{array}$} & $\begin{array}{ll}10 & -5 \\
-10 & \end{array}$ & Traditional care \\
\hline
\end{tabular}

showed significantly less pain in patients who underwent FTS. Moreover, Wang et al. [16] included the serum parameters after surgery. The C-reactive protein and interleukin-6 levels were significantly lower in the FTS group. Additionally, the quality of life after surgery and in-hospital costs were reported by one [18] and two studies [18,20], respectively. Vlug et al. [18] showed no significant differences in these outcomes between the two groups; however, Feng et al. [20] showed that FTS was associated with significantly lower medical costs.

\section{Discussion}

Over the past 20 years, FTS and laparoscopic techniques have become the two primary methods of reducing surgical stress and improving recovery after colorectal surgery, thus providing better short-term outcomes. Combining the two approaches would hypothetically result in the most rapid recovery. Thus, we conducted the present study to provide evidence in support of this theory. Our results suggest that both the postoperative hospital stay, time to first bowel movement and the time to first flatus were shorter in the FTS group than in the traditional care group after laparoscopic colorectal surgery. Two recent meta-analyses $[11,26]$ that compared FTS with traditional care for all types of colorectal surgery suggested that hospital stays were shorter in the FTS group, which is in agreement with our findings. Furthermore, because both FTS and laparoscopy can reduce surgical stress and improve recovery, incorporation of FTS into laparoscopic surgery is not superfluous and may have a combined effect in enhancing recovery and shortening the postoperative hospital stay.

Safety is always of utmost concern in clinical practice. Although reducing the complication rate is one of the aims of FTS, concerns have been expressed about the increased risk of severe complications such as pulmonary embolism and anastomotic leakage [27]. Previous metaanalysis of FTS in all types of colorectal surgery suggested that FTS neither compromise nor enhance safety $[11,26]$. However, our results suggest that FTS is associated with a significantly lower complication rate than traditional care is. This is a surprising result. First, this

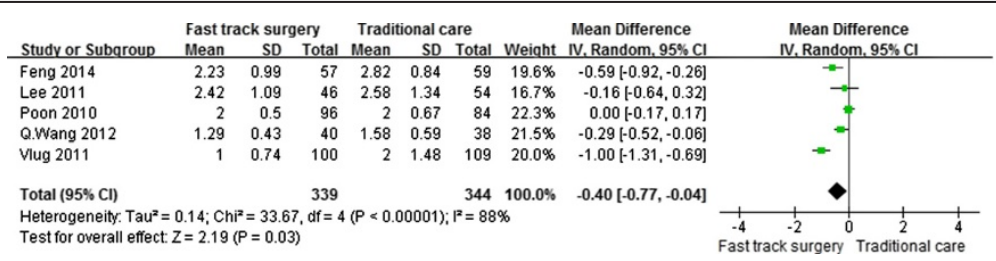

Figure 3 Meta-analysis of time to first flatus. 


\begin{tabular}{|c|c|c|c|c|c|c|c|c|c|c|}
\hline \multirow[b]{2}{*}{ Study or Subqroup } & \multicolumn{3}{|c|}{ Fast track surgery } & \multicolumn{3}{|c|}{ Traditional care } & \multirow{2}{*}{ Weight } & \multirow{2}{*}{$\begin{array}{l}\text { Mean Difference } \\
\text { IV, Random, } 95 \% \mathrm{Cl}\end{array}$} & \multirow{2}{*}{\multicolumn{2}{|c|}{$\begin{array}{l}\text { Mean Difference } \\
\text { IV, Random, } 95 \% \mathrm{Cl}\end{array}$}} \\
\hline & Mean & SD & Total & Mean & SD & Total & & & & \\
\hline \multicolumn{11}{|l|}{ 3.1.1 RCT } \\
\hline Feng 2014 & 2.72 & 0.93 & 57 & 3.62 & 1.04 & 59 & $19.0 \%$ & $-0.90[-1.26,-0.54]$ & $\rightarrow$ & \\
\hline Lee 2011 & 4.71 & 2.1 & 46 & 5 & 1.82 & 54 & $13.4 \%$ & $-0.29[-1.07,0.49]$ & & - \\
\hline Q.Wang 2012 & 2.29 & 0.462 & 40 & 2.67 & 0.62 & 38 & $20.2 \%$ & $-0.38[-0.62,-0.14]$ & - & \\
\hline Vlug 2011 & 2 & 2.22 & 100 & 3 & 1.48 & 109 & $16.9 \%$ & $-1.00[-1.52,-0.48]$ & - & \\
\hline Subtotal $(95 \% \mathrm{Cl})$ & & & 243 & & & 260 & $69.4 \%$ & $-0.66[-1.02,-0.30]$ & & \\
\hline \multicolumn{11}{|c|}{$\begin{array}{l}\text { Heterogeneity: } \text { Tau }^{2}=0.08 ; \mathrm{Chi}^{2}=8.72, \mathrm{df}=3(P=0.03) ; \mathrm{l}^{2}=66 \% \\
\text { Test for overall effect: } Z=3.57(P=0.0004)\end{array}$} \\
\hline \multicolumn{11}{|l|}{$3.1 .2 \mathrm{CCT}$} \\
\hline Gouvas 2012 & 2 & 1.5 & 42 & 5 & 2.5 & 33 & $11.1 \%$ & $-3.00[-3.97,-2.03]$ & & \\
\hline Vassiliki 2009 & 2 & 0.74 & 82 & 3 & 1.48 & 115 & $19.5 \%$ & $-1.00[-1.31,-0.69]$ & - & \\
\hline Subtotal $(95 \% \mathrm{Cl})$ & & & 124 & & & 148 & $30.6 \%$ & $-1.95[-3.90,0.01]$ & & \\
\hline \multicolumn{11}{|c|}{$\begin{array}{l}\text { Heterogeneity: } \text { Tau }^{2}=1.87 ; \mathrm{Chi}^{2}=14.89, \mathrm{df}=1(\mathrm{P}=0.0001) ; \mathrm{I}^{2}=93 \% \\
\text { Test for overall effect: } Z=1.95(P=0.05)\end{array}$} \\
\hline Total $(95 \% \mathrm{Cl})$ & & & 367 & & & 408 & $100.0 \%$ & $-0.98[-1.45,-0.52]$ & & \\
\hline \multicolumn{9}{|c|}{$\begin{array}{l}\text { Heterogeneity: } \mathrm{Tau}^{2}=0.26 ; \mathrm{Chi}^{2}=35.04, \mathrm{df}=5(\mathrm{P}<0.00001) ; \mathrm{I}^{2}=86 \% \\
\text { Test for overall effect: } Z=4.16(P<0.0001) \\
\text { Test for subgroup differences: } \mathrm{Chi}^{2}=1.61 . \mathrm{df}=1(\mathrm{P}=0.20) . \mathrm{I}^{2}=37.9 \%\end{array}$} & $\begin{array}{ccc}-4 & -2 & 0 \\
\text { Fast track surgery }\end{array}$ & $\begin{array}{lcc} & 1 & 4 \\
0 & 2 & 4 \\
\text { Traditional care }\end{array}$ \\
\hline
\end{tabular}

finding may have been caused by the adequate fast-track elements in the included studies. Second, this result may have been associated with the combined effect of laparoscopic techniques and FTS with available expertise of the medical team $[2,28]$. Another concern about FTS is the potentially higher readmission rate reported by some hospitals [29]. After pooling the data, FTS was associated with a relatively lower readmission rate. This finding may be attributed to the rigid and strict discharge criteria in the FTS protocols of the included studies [11].

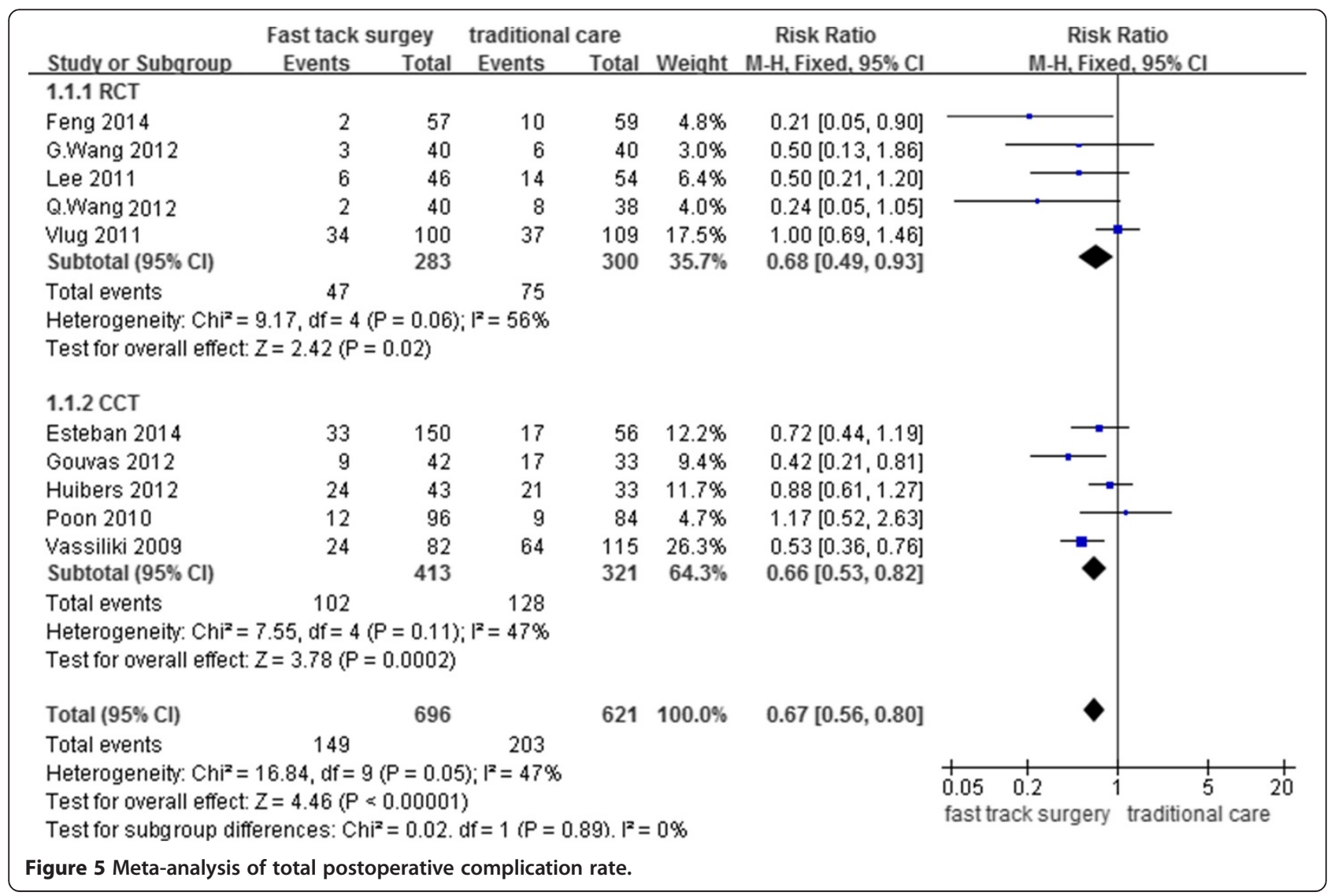




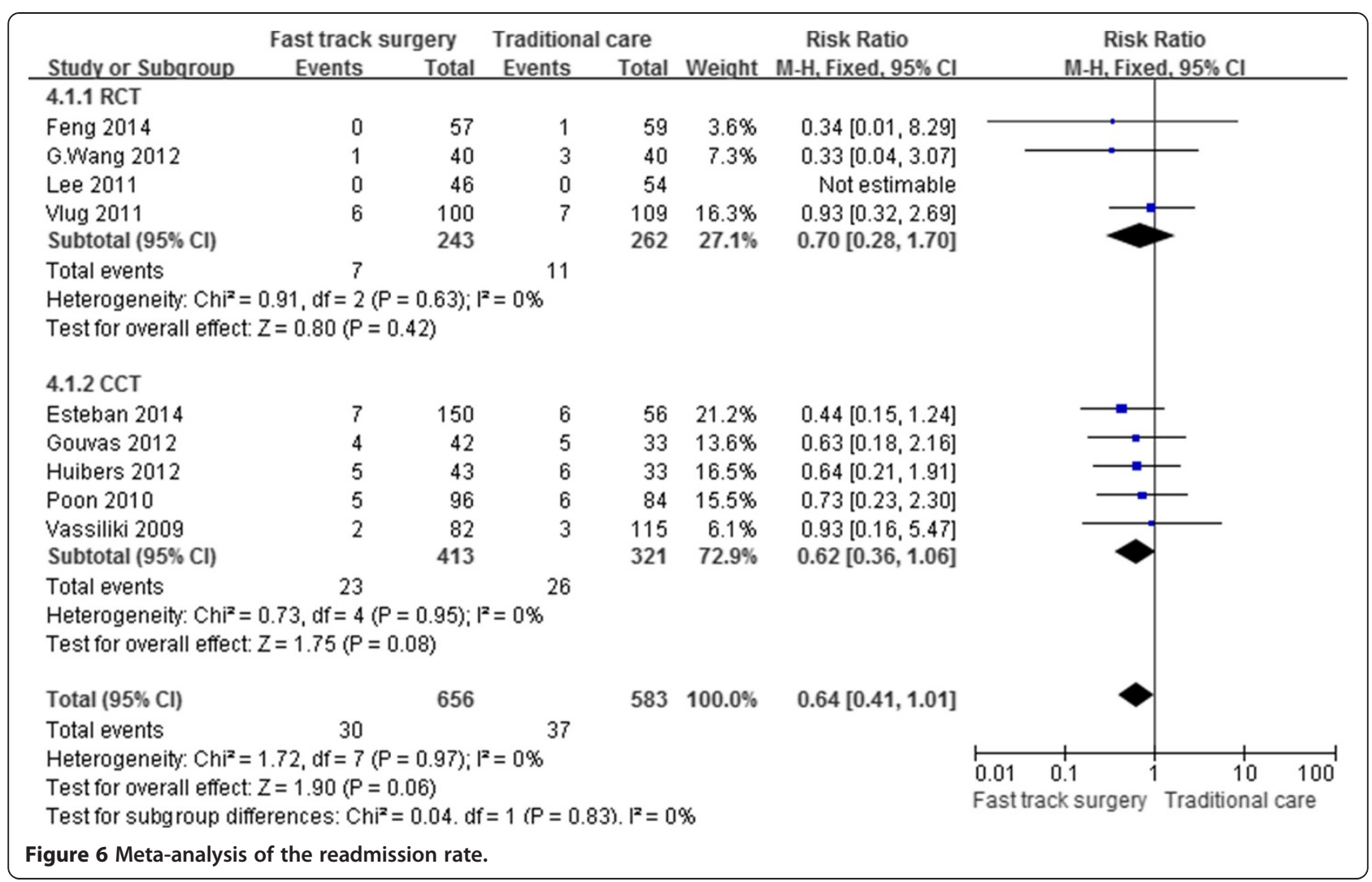

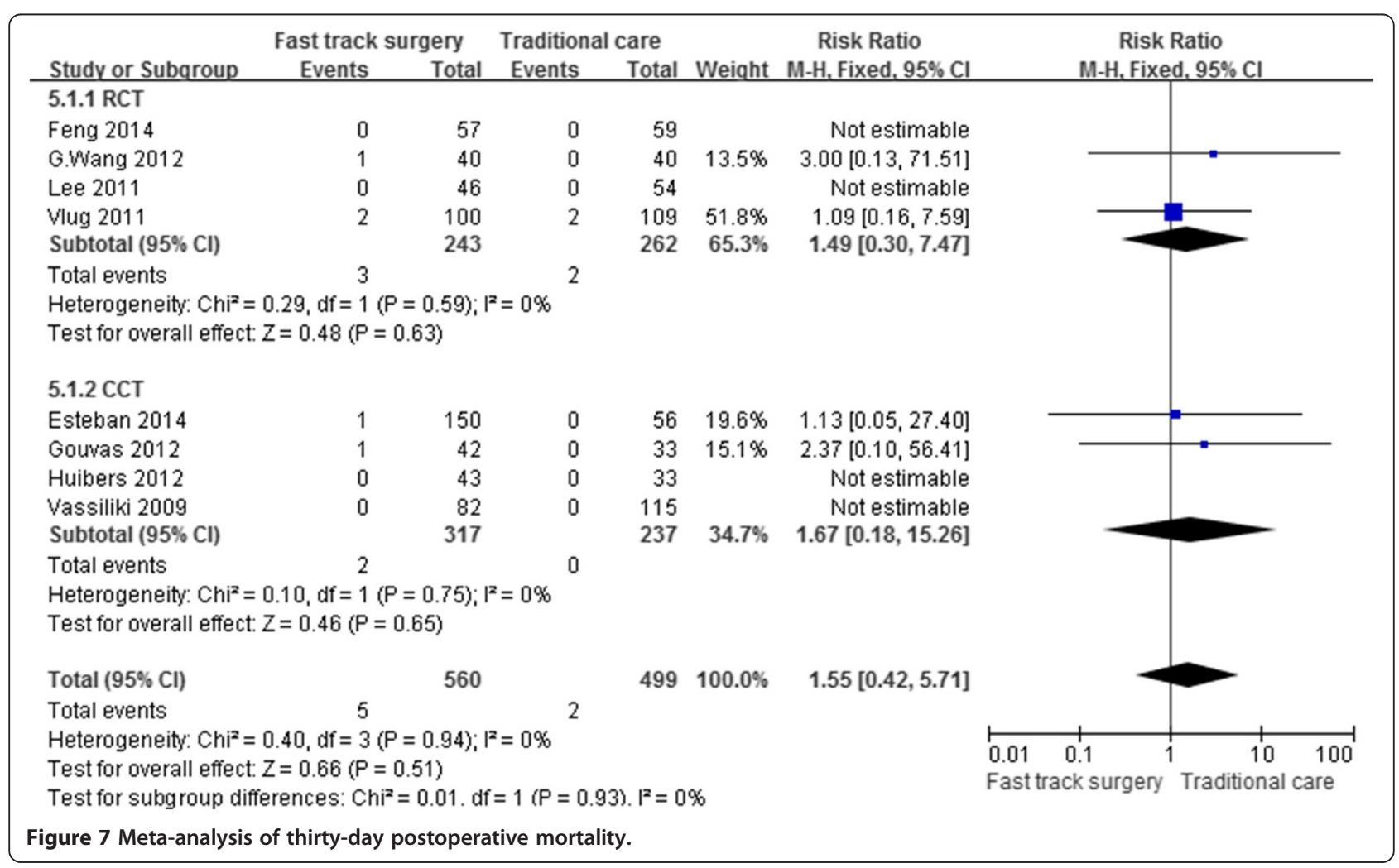


Table 5 The results of subgroup analysis based on fast track elements

\begin{tabular}{|c|c|c|c|c|}
\hline \multirow[t]{2}{*}{ Factor } & \multicolumn{2}{|c|}{ OR for postoperative complication rate } & \multicolumn{2}{|c|}{ WMD for postoperative hospital stay } \\
\hline & Studies with the element & Studies without the element & Studies with the element & Studies without the element \\
\hline A & $0.69(0.57-0.82), I^{2}=43 \%$ & $0.21(0.05-0.90)_{,}^{*}$ & $-1.61(-2.29,-0.92),\left.\right|^{2}=82 \%$ & $-1.93(-2.61,-1.25),{ }^{*}$ \\
\hline B & $0.70(0.56-0.87), I^{2}=50 \%$ & $0.60(0.44-0.83), I^{2}=38 \%$ & $-2.18(-3.06,-1.31),\left.\right|^{2}=81 \%$ & $-0.94(-1.27,-0.60), I^{2}=1 \%$ \\
\hline C & $0.67(0.49-0.93), I^{2}=52 \%$ & $0.62(0.40-0.95), I^{2}=49 \%$ & $-1.68(-2.35,-1.01), I^{2}=79 \%$ & $-1.61(-3.52,0.29), I^{2}=89 \%$ \\
\hline D & $0.86(0.66-1.13), I^{2}=43 \%$ & $0.57(0.45-0.72), I^{2}=12 \%$ & $-1.34(-1.77,-0.91),\left.\right|^{2}=11 \%$ & $-1.81(-2.67,-0.95), I^{2}=86 \%$ \\
\hline E & $0.75(0.61-0.92),\left.\right|^{2}=34 \%$ & $0.48(0.33-0.69), I^{2}=33 \%$ & $-1.75(-2.61,-0.88), 1^{2}=84 \%$ & $-1.43(-2.34,-0.52), I^{2}=80 \%$ \\
\hline $\mathrm{F}$ & $0.69(0.52-0.91), I^{2}=48 \%$ & $0.62(0.41-0.94), I^{2}=53 \%$ & $-4.00(-4.93,-3.07), I^{2}=0 \%$ & $-1.20(-1.44,-0.95), I^{2}=42 \%$ \\
\hline G & $0.71(0.50-1.02), I^{2}=55 \%$ & $0.56(0.42-0.76), I^{2}=13 \%$ & $-2.63(-3.98,-1.27),\left.\right|^{2}=88 \%$ & $-1.10(-1.38,-0.82),\left.\right|^{2}=23 \%$ \\
\hline $\mathrm{H}$ & $0.74(0.60-0.93), I^{2}=42 \%$ & $0.56(0.41-0.76), I^{2}=41 \%$ & $-2.28(-3.45,-1.10), 1^{2}=85 \%$ & $-1.11(-1.68,-0.55), I^{2}=65 \%$ \\
\hline । & $0.82(0.41-1.63), I^{2}=56 \%$ & $0.58(0.42-0.72), I^{2}=27 \%$ & $-1.10(-2.09,-0.12), I^{2}=74 \%$ & $-1.96(-2.80,-1.13), I^{2}=86 \%$ \\
\hline J & $1.00(0.69,1.46),^{*}$ & $0.59(0.48,0.73), I^{2}=37 \%$ & $-1.00(-1.76,-0.24)_{1}^{*}$ & $-1.74(-2.43,-1.05), I^{2}=83 \%$ \\
\hline K & $0.78(0.63-0.96), I^{2}=24 \%$ & $0.45(0.31-0.64), I^{2}=19 \%$ & $-1.82(-2.99,-0.65),\left.\right|^{2}=87 \%$ & $-1.43(-1.95,-0.91),\left.\right|^{2}=64 \%$ \\
\hline$L$ & $0.81(0.62-1.07), I^{2}=33 \%$ & $0.56(0.44-0.71),\left.\right|^{2}=50 \%$ & $-1.64(-2.79,-0.49), I^{2}=83 \%$ & $-1.58(-2.32,-0.84), I^{2}=82 \%$ \\
\hline M & - & - & - & - \\
\hline $\mathrm{N}$ & - & - & - & - \\
\hline $\mathrm{O}$ & $0.71(0.46-1.08), I^{2}=69 \%$ & $0.60(0.44-0.82), I^{2}=17 \%$ & $-1.29(-1.88,-0.70), 1^{2}=64 \%$ & $-1.90(-2.95,-0.86), I^{2}=86 \%$ \\
\hline$P$ & $0.79(0.63-0.99), I^{2}=27 \%$ & $0.53(0.40-0.71), I^{2}=30 \%$ & $-1.74(-2.67,-0.81),\left.\right|^{2}=85 \%$ & $-1.58(-2.85,-0.58),\left.\right|^{2}=82 \%$ \\
\hline Q & $0.69(0.57-0.83), I^{2}=44 \%$ & $0.42(0.21-0.81),{ }^{*}$ & $-1.42(-1.97,-0.87),\left.\right|^{2}=77 \%$ & $-4.00(-5.45,-2.55),{ }^{*}$ \\
\hline
\end{tabular}

A: patients education B: preoperative feeding C: No bowel preparation D: No premedication E: fluid restriction F: high $\mathrm{O} 2$ concentration during operation G: prevention of hypothermia $\mathrm{H}$ : epidural analgesia I: wound infiltration with local analgesia J: minimally invasive incisions K: No routine use of NG tube L: No routine use of drains M: early mobilization N:enforced early postoperative oral feeding O: No morphine use P: standard laxatives Q: early remove bladder catheter. "**" only one study in the subgroup, no $\mathrm{I}^{2}$ could be provided. "-" all the including studies contain the element. The results without significant difference is marked by bold type.

Based on our results, we can conclude that FTS is feasible and can enhance safety after laparoscopic colorectal cancer surgery. Adequate fast-track elements and rigid and strict discharge criteria are two important factors that contribute to this conclusion.

As mentioned above, adequate fast-track elements applied in the included studies were an important prerequisite for the encouraging results. This is also why we excluded studies with fewer than six fast-track elements. We did not include the study by Chalabi et al. [30] because they applied a "RAPID protocol", which is a simplified fast-track protocol that contains only three fast-track elements. However, distinctions among the fast-track elements were not preventable among the included studies. This may also explain the heterogeneity in some outcome measures.

Thus, to provide better evidence, we performed a subgroup analysis based on each fast-track element for two major outcomes: the duration of the postoperative hospital stay and the total postoperative complication rate, each of which can separately represent the efficacy and safety of FTS. Our results indicate the importance of the fast-track element "no bowel preparation" because the difference in the duration of the postoperative hospital stay between the FTS and traditional care group was not significant in the studies without the element "no bowel preparation". Two comprehensive studies also suggested that bowel preparation is unnecessary [31,32]. Several RCTs showed that bowel preparation was associated with a prolonged hospital stay and higher complication rate $[33,34]$. Therefore, "no bowel preparation" should be a priority when establishing a fast-track protocol in the future. Additionally, differences in the total postoperative complication rate between the FTS and traditional care group were not significant in the subgroup analysis of many elements. Notably, subgroup analysis results of the element "wound infiltration with local analgesia" deviated greatly from statistical significance (OR, 0.82 [0.41-1.63]; $\mathrm{p}=0.57$ ). At the same time, the effect of local infiltration analgesia is questionable [35]. RCTs and meta-analysis on this topic have also shown controversial results [36-38]. Therefore, we do not recommend integration of the element "wound infiltration with local analgesia" into FTS. More high-quality RCTs are required to provide more solid evidence regarding this element.

Another issue regarding the fast-track elements is that no presented FTS guidelines are particular for laparoscopic surgery, and some useful fast-track elements are debatable in laparoscopic surgery. In particular, epidural analgesia has been proven to provide better pain relief, reduce perioperative stress, reduce postoperative 
complications, and shorten the hospital stay after open surgery [6,39]; however, its role in laparoscopic surgery remains controversial. On one hand, six studies used epidural analgesia, which showed wide acceptance. The beneficial effect of epidural analgesia in pain control has also been confirmed by many studies $[40,41]$. On the other hand, epidural analgesia during laparoscopic surgery is not advocated by some authors. The meta-analysis conducted by Levy et al. [40] suggested that no analgesia protocol showed more overall benefits than did other protocols during laparoscopic surgery. Another meta-analysis showed that epidural analgesia fails to shorten the hospital stay following laparoscopic colorectal surgery [41]. Moreover, even Kehlet [2], who initiated FTS, demonstrated that epidural analgesia might not be necessary in laparoscopic colorectal surgery and can be replaced by nonopioid analgesia. Given the limited number of studies in this specific clinical area, more evidence is required to determine the role of epidural analgesia in the fast-track protocol for laparoscopic colorectal surgery.

Patient selection is also a debatable issue in FTS. Feroci et al. [42] suggested that patients $>75$ years of age with an American Society of Anesthesiologists (ASA) physical status score of 3 or 4 have high complication rates, prolonged hospital stays, and negative compliance. Male sex is another predictor of negative compliance. Among the included studies, the baseline characteristics were comparable between the FTS and control groups in the studies published by Poon et al. [22], Vassiliki et al. [24], and all RCTs. Compared with the traditional care group, Gouvas et al. [21] enrolled more male patients, Esteban et al. [23] enrolled more patients with high ASA scores, and Huibers et al. [25] enrolled more patients with advanced-stage tumors in the FTS group. Male sex, a high ASA score, and advanced-stage tumors were factors associated with poor outcomes. Thus, the effect of FTS may have been more significant without these baseline differences. The differences in patient selection among the different studies is another issue. Wang et al. [16] focused on elderly patients with a higher mean age than in other studies. Vassiliki et al. [24] enrolled more patients with ASA scores of 3 and 4 . The ratio of patients with advanced-stage tumors in the study by Poon et al. [22] was also relatively higher than in other studies. Although all of these studies showed results favoring FTS, the above-mentioned differences may be another factor that contributed to the heterogeneity.

A previous meta-analysis [43] was conducted on this topic. In contrast to their study, we included CCTs and one new RCT [20]. We also excluded three RCTs [44-46] that were included in the above-mentioned meta-analysis by mistake. Most importantly, we excluded the study by Wang [44] because in that study, FTS and traditional care were compared in all types of colorectal surgery, not only in laparoscopic surgery. We also excluded the studies by van Bree [45] and Veenhof [46] because they exhibited overlap of patients and authors with the study by Vlug [18]. Thus, we suppose that our study provides better evidence.

Several limitations of this meta-analysis should be considered. First, some variables such as the skill and experience of the operating surgeon, efficacy of perioperative care, and quality of anesthesia may have differed between the FTS and traditional care groups. Thus, further highquality, large-scale, and multicenter RCTs should be performed with consideration of these differences between the two groups. Second, 5 of 10 studies were not RCTs, which may have compromised the statistical power. Third,

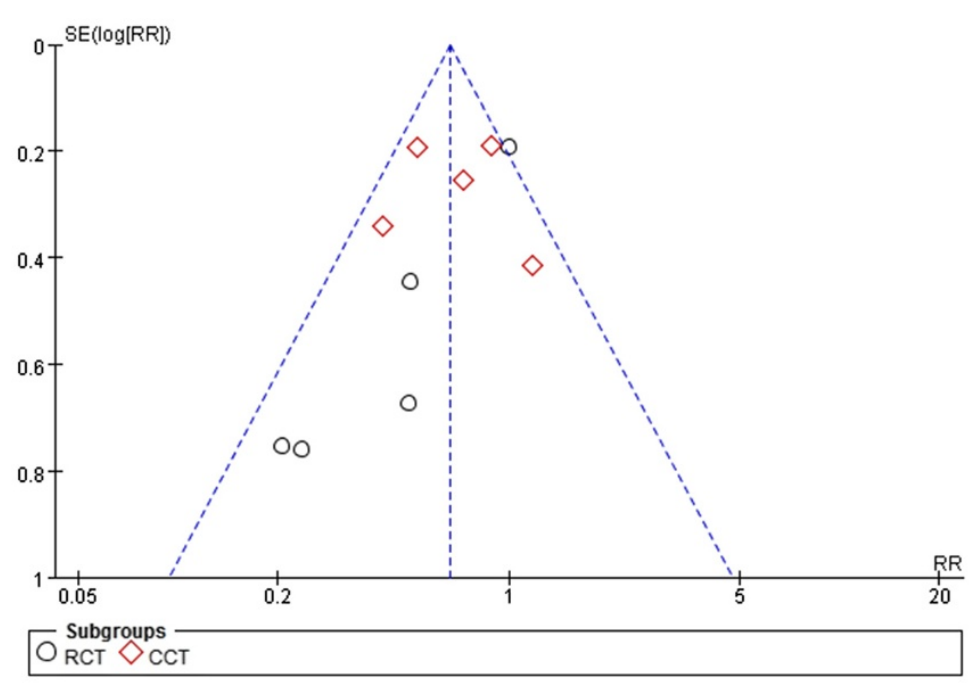

Figure 8 Funnel plot of the studies on the rate of postoperative complications. 
the surgery type varied among the studies, and subgroup analysis was not performed because of unextractable data. Finally, as mentioned above, considerable heterogeneity was observed in our study. Despite of these limitations, our meta-analysis shows some favorable results and conclusions regarding the effects of FTS after laparoscopic colorectal surgery. In particular, we found that FTS can enhance safety. At the same time, no obvious publication bias was observed by performing a funnel plot on the rate of postoperative complications (Figure 8).

\section{Conclusion}

In laparoscopic colorectal cancer surgery, FTS can significantly shorten the postoperative hospital stay, accelerate the postoperative recovery, and, notably, enhance safety when compared with traditional care. In the future, more high-quality and well-designed studies are needed to provide more solid evidence.

\section{Abbreviations \\ FTS: Fast-track surgery; RCTs: Randomized controlled trials; FT: Fast track; CCTs: Controlled clinical trials; WMD: Weighted mean difference; Cls: Confidence intervals; SD: Standard deviations; IQR: Interquartile range.}

\section{Competing interests}

All the authors (Jun-hua Zhao, Jing-xu Sun, Peng Gao, Xiao-wan Chen, Yong-xi Song, Xuan-zhang Huang, Hui-mian Xu and Zhen-ning Wang) declare that they have no competing interests.

\section{Authors' contributions}

JZ and JS contributed equally to this work. ZW participated in the conception and design of the study and coordination; JZ and JS participated in design of the study, data extraction, article selection and manuscript preparation and interpreted the results in collaboration with $\mathrm{XH}$ and $\mathrm{PG}$; $\mathrm{XC}$ and HX participated in data extraction, article selection and data extraction; YS performed the statistical analysis and participated in the critical revision of the manuscript. All authors drafted and critically revised the manuscript and approved the final version.

\section{Acknowledgements}

This work was supported by National Science Foundation of China (No. 81201888, 81372549 and No. 81172370), Specialized Research Fund for the Doctoral Program of Higher Education (No. 20122104110009) and the Project of Science and Technology of Shenyang (F12-193-9-08).

\section{Disclosures}

Have no conflicts of interest or financial ties to disclose.

Received: 6 June 2014 Accepted: 20 August 2014

Published: 23 August 2014

\section{References}

1. Jemal A, Bray F, Center MM, Ferlay J, Ward E, Forman D: Global cancer statistics. CA 2011, 61(2):69-90.

2. Kehlet H: Fast-track colorectal surgery. Lancet 2008, 371(9615):791-793.

3. Fowler DL, White SA: Laparoscopy-assisted sigmoid resection. Surg Laparosc Endosc 1991, 1(3):183-188.

4. Schwenk W, Haase O, Neudecker J, Muller JM: Short term benefits for laparoscopic colorectal resection. Cochrane Database Syst Rev 2005 3. CD003145.

5. Noel JK, Fahrbach K, Estok R, Cella C, Frame D, Linz H, Cima RR, Dozois EJ, Senagore AJ: Minimally invasive colorectal resection outcomes: short-term comparison with open procedures. J Am Coll Surg 2007, 204(2):291-307.

6. Wilmore DW, Kehlet $\mathrm{H}$ : Management of patients in fast track surgery. BMJ 2001, 322(7284):473-476.
7. Kehlet $\mathrm{H}$, Wilmore DW: Multimodal strategies to improve surgical outcome. Am J Surg 2002, 183(6):630-641.

8. Gatt M, Anderson AD, Reddy BS, Hayward-Sampson P, Tring IC, MacFie J: Randomized clinical trial of multimodal optimization of surgical care in patients undergoing major colonic resection. Br J Surg 2005, 92(11):1354-1362.

9. Ren L, Zhu D, Wei Y, Pan X, Liang L, Xu J, Zhong Y, Xue Z, Jin L, Zhan S, Niu W, Qin X, Wu Z, Wu Z, Niu W, Qin X, Wu Z, Wu Z: Enhanced Recovery After Surgery (ERAS) program attenuates stress and accelerates recovery in patients after radical resection for colorectal cancer: a prospective randomized controlled trial. World J Surg 2012, 36(2):407-414.

10. Wind J, Polle SW, Fung Kon Jin PH, Dejong $\mathrm{CH}$, von Meyenfeldt MF, Ubbink DT, Gouma DJ, Bemelman WA, Laparoscopy and/or Fast Track Multimodal Management Versus Standard Care Study G, Enhanced Recovery after Surgery G: Systematic review of enhanced recovery programmes in colonic surgery. Br J Surg 2006, 93(7):800-809.

11. Gouvas N, Tan E, Windsor A, Xynos E, Tekkis PP: Fast-track vs standard care in colorectal surgery: a meta-analysis update. Int J Colorectal Dis 2009, 24(10):1119-1131.

12. Slim K, Fingerhut A: Laparoscopy or fast-track surgery, or both? Surg Endosc 2009, 23(3):465-466.

13. Kehlet $\mathrm{H}$ : Interpretation of meta-analyses of laparoscopic versus open colorectal surgery? Dis Colon Rectum 2013, 56(8):e364-e365.

14. Grobmyer SR, Pieracci FM, Allen PJ, Brennan MF, Jaques DP: Defining morbidity after pancreaticoduodenectomy: use of a prospective complication grading system. J Am Coll Surg 2007, 204(3):356-364.

15. Hozo SP, Djulbegovic B, Hozo I: Estimating the mean and variance from the median, range, and the size of a sample. BMC Med Res Meth 2005, $5: 13$.

16. Wang Q, Suo J, Jiang J, Wang C, Zhao YQ, Cao X: Effectiveness of fast-track rehabilitation vs conventional care in laparoscopic colorectal resection for elderly patients: a randomized trial. Colorectal Dis 2012, 14(8):1009-1013.

17. Wang G, Jiang Z, Zhao K, Li G, Liu F, Pan H, Li J: Immunologic response after laparoscopic colon cancer operation within an enhanced recovery program. J Gastrointest Surg 2012, 16(7):1379-1388.

18. Vlug MS, Wind J, Hollmann MW, Ubbink DT, Cense HA, Engel AF, Gerhards MF, van Wagensveld BA, van der Zaag ES, van Geloven AA, Sprangers MA, Cuesta MA, Bemelman WA, LAFA study group: Laparoscopy in combination with fast track multimodal management is the best perioperative strategy in patients undergoing colonic surgery: a randomized clinical trial (LAFA-study). Ann Surg 2011, 254(6):868-875.

19. Lee TG, Kang SB, Kim DW, Hong S, Heo SC, Park KJ: Comparison of early mobilization and diet rehabilitation program with conventional care after laparoscopic colon surgery: a prospective randomized controlled trial. Dis Colon Rectum 2011, 54(1):21-28.

20. Feng F, Li XH, Shi H, Wu GS, Zhang HW, Liu XN, Zhao QC: Fast-track surgery combined with laparoscopy could improve postoperative recovery of low-risk rectal cancer patients: a randomized controlled clinical trial. J Dig Dis 2014, 15(6):306-313.

21. Gouvas N, Gogos-Pappas G, Tsimogiannis K, Tsimoyiannis E, Dervenis C, Xynos E: Implementation of fast-track protocols in open and laparoscopic sphincter-preserving rectal cancer surgery: a multicenter, comparative, prospective, non-randomized study. Dig Surg 2012, 29(4):301-309.

22. Poon JT, Fan JK, Lo OS, Law WL: Enhanced recovery program in laparoscopic colectomy for cancer. Int J Colorectal Dis 2011, 26(1):71-77.

23. Esteban F, Cerdan FJ, Garcia-Alonso M, Sanz-Lopez R, Arroyo A, Ramirez JM Moreno C, Morales R, Navarro A, Fuentes M: A multicentre comparison of a fast track or conventional postoperative protocol following laparoscopic or open elective surgery for colorectal cancer surgery. Colorectal Dis 2014, 16(2):134-140

24. Tsikitis VL, Holubar SD, Dozois EJ, Cima RR, Pemberton JH, Larson DW: Advantages of fast-track recovery after laparoscopic right hemicolectomy for colon cancer. Surg Endosc 2010, 24(8):1911-1916.

25. Huibers CJ, de Roos MA, Ong KH: The effect of the introduction of the ERAS protocol in laparoscopic total mesorectal excision for rectal cancer. Int J Colorectal Dis 2012, 27(6):751-757.

26. Zhuang $C L$, Ye XZ, Zhang XD, Chen BC, Yu Z: Enhanced recovery after surgery programs versus traditional care for colorectal surgery: a meta-analysis of randomized controlled trials. Dis Colon Rectum 2013, 56(5):667-678.

27. Kehlet H, Wilmore DW: Fast-track surgery. Br J Surg 2005, 92(1):3-4. 
28. Soop M: Multimodal rehabilitation in the laparoscopic era: still worth it? Dis Colon Rectum 2011, 54(1):1-2.

29. Basse L, Thorbol JE, Lossl K, Kehlet H: Colonic surgery with accelerated rehabilitation or conventional care. Dis Colon Rectum 2004, 47(3):271-277. discussion 277-278

30. Al Chalabi H, Kavanagh DO, Hassan L, Donnell KO, Nugent E, Andrews E, Keane FB, O'Riordain DS, Miller A, Neary P: The benefit of an enhanced recovery programme following elective laparoscopic sigmoid colectomy. Int J Colorectal Dis 2010, 25(6):761-766.

31. Guenaga KF, Matos D, Wille-Jorgensen P: Mechanical bowel preparation for elective colorectal surgery. Cochrane Database Syst Rev 2011, 9, CD001544.

32. Slim K, Vicaut E, Panis Y, Chipponi J: Meta-analysis of randomized clinical trials of colorectal surgery with or without mechanical bowel preparation. Br J Surg 2004, 91(9):1125-1130.

33. Zmora O, Mahajna A, Bar-Zakai B, Rosin D, Hershko D, Shabtai M, Krausz MM, Ayalon A: Colon and rectal surgery without mechanical bowel preparation: a randomized prospective trial. Ann Surg 2003, 237(3):363-367.

34. Bucher P, Gervaz P, Soravia C, Mermillod B, Erne M, Morel P: Randomized clinical trial of mechanical bowel preparation versus no preparation before elective left-sided colorectal surgery. Br J Surg 2005, 92(4):409-414.

35. Dahl JB, Moiniche S: Relief of postoperative pain by local anaesthetic infiltration: efficacy for major abdominal and orthopedic surgery. Pain 2009, 143(1-2):7-11.

36. Lunn TH, Husted $H$, Solgaard S, Kristensen BB, Otte KS, Kjersgaard AG, Gaarn-Larsen L, Kehlet H: Intraoperative local infiltration analgesia for early analgesia after total hip arthroplasty: a randomized, double-blind, placebo-controlled trial. Reg Anesth Pain Med 2011, 36(5):424-429.

37. Ventham NT, O'Neill S, Johns N, Brady RR, Fearon KC: Evaluation of novel local anesthetic wound infiltration techniques for postoperative pain following colorectal resection surgery: a meta-analysis. Dis Colon Rectum 2014, 57(2):237-250.

38. Gupta A, Favaios S, Perniola A, Magnuson A, Berggren L: A meta-analysis of the efficacy of wound catheters for post-operative pain management. Acta Anaesthesio/ Scand 2011, 55(7):785-796

39. White PF, Kehlet H, Neal JM, Schricker T, Carr DB, Carli F, Fast-Track Surgery Study G: The role of the anesthesiologist in fast-track surgery: from multimodal analgesia to perioperative medical care. Anesth Analg 2007, 104(6):1380-1396. table of contents.

40. Levy BF, Tilney HS, Dowson HM, Rockall TA: A systematic review of postoperative analgesia following laparoscopic colorectal surgery. Colorectal Dis 2010, 12(1):5-15.

41. Khan SA, Khokhar HA, Nasr AR, Carton E, El-Masry S: Effect of epidural analgesia on bowel function in laparoscopic colorectal surgery: a systematic review and meta-analysis. Surg Endosc 2013, 27(7):2581-2591.

42. Feroci F, Lenzi E, Baraghini M, Garzi A, Vannucchi A, Cantafio S, Scatizzi M: Fast-track surgery in real life: how patient factors influence outcomes and compliance with an enhanced recovery clinical pathway after colorectal surgery. Surg Laparosc Endosc Percutan Tech 2013, 23(3):259-265.

43. Li P, Fang F, Cai JX, Tang D, Li QG, Wang DR: Fast-track rehabilitation vs conventional care in laparoscopic colorectal resection for colorectal malignancy: a meta-analysis. World J Gastroenterol 2013, 19(47):9119-9126.

44. Wang G, Jiang ZW, Xu J, Gong JF, Bao Y, Xie LF, Li JS: Fast-track rehabilitation program vs conventional care after colorectal resection: a randomized clinical trial. World J Gastroenterol 2011, 17(5):671-676.
45. van Bree SH, Vlug MS, Bemelman WA, Hollmann MW, Ubbink DT, Zwinderman AH, de Jonge WJ, Snoek SA, Bolhuis $\mathrm{K}$, van der Zanden E, The FO, Bennink RJ, Boeckxstaens GE: Faster recovery of gastrointestinal transit after laparoscopy and fast-track care in patients undergoing colonic surgery. Gastroenterology 2011, 141(3):872-880. e871-874.

46. Veenhof $A A$, Vlug $M S$, van der Pas $M H$, Sietses $C$, van der Peet $D L$, de Lange-de Klerk ES, Bonjer HJ, Bemelman WA, Cuesta MA: Surgical stress response and postoperative immune function after laparoscopy or open surgery with fast track or standard perioperative care: a randomized trial. Ann Surg 2012, 255(2):216-221.

doi:10.1186/1471-2407-14-607

Cite this article as: Zhao et al.: Fast-track surgery versus traditional perioperative care in laparoscopic colorectal cancer surgery: a meta-analysis. BMC Cancer 2014 14:607.

\section{Submit your next manuscript to BioMed Central and take full advantage of:}

- Convenient online submission

- Thorough peer review

- No space constraints or color figure charges

- Immediate publication on acceptance

- Inclusion in PubMed, CAS, Scopus and Google Scholar

- Research which is freely available for redistribution

Submit your manuscript at www.biomedcentral.com/submit
C Biomed Central 